\title{
ADEQUAÇÃO DO MIX DE CARVÕES PARA AS COQUERIAS EM FUNÇÃO DO CENÁRIO ATUAL DE CARVÕES*
}

\author{
Diego Canez Fernandes ${ }^{1}$ \\ Marcello Barros Sabadini2 \\ Henriquison Magela Bottrel Reis ${ }^{3}$
}

\section{Resumo}

O atual cenário mundial do mercado de carvões e da fabricação de aço vem estimulando mudanças no mix de carvões praticados na Usiminas. Neste contexto, foram realizadas alterações significativas no mix, com destaque para o aumento da participação de carvões alto voláteis e coque verde de petróleo. A qualidade do coque foi mantida por meio de ajustes de parâmetros operacionais na britagem, aliados à adição de óleo na mistura. O objetivo desse trabalho é apresentar a evolução do consumo desses materiais e os resultados de qualidade do coque. Os resultados de qualidade do coque (DI15/150, CSR e CRI) não sofreram variações significativas com a elevação da participação dos carvões alto voláteis e coque verde de petróleo, mantendo-se dentro da faixa visada.

Palavras-chave: Mix de carvões; Adição de óleo; Qualidade de coque.

\section{CHANGES AT MIX OF COALS FOR COKE OVENS IN FUNCTION OF CURRENT SCENARIO OF COALS}

\section{Abstract}

The current global market scenario of coals and steel manufacturing, has spurred changes in the mix of coals practiced in Usiminas. In this context, significant changes were made in the mix, highlighting the increased participation of high volatile coals and petroleum coke. The coke quality was maintained by adjusting the operating parameters in crushing, combined with the addition of oil in mixture. The aim of this paper is to present the evolution of the consumption of these materials and the results of coke quality. The results of coke quality (DI15/150, CSR and CRI) do not show significant variation with increasing participation of high volatile and petroleum coke, keeping within the target range.

Keywords: Mix coals; Addition of oil; Coke quality.

1 Engenheiro Metalurgista, Engenheiro de Produção, Gerência Técnica de Redução, Usiminas, Ipatinga, Minas Gerais, Brasil.

2 Engenheiro Metalurgista, Engenheiro de Produção Sênior, Gerência Técnica de Redução, Usiminas, Ipatinga, Minas Gerais, Brasil.

3 Engenheiro Metalurgista, M.Sc., Pesquisador Especialista, Gerência de Pesquisa e Desenvolvimento de Processos, Centro de Tecnologia Usiminas, Ipatinga, Minas Gerais, Brasil.

\footnotetext{
* Contribuição técnica ao $44^{\circ}$ Seminário de Redução de Minério de Ferro e Matérias-primas, 15ํ Simpósio Brasileiro de Minério de Ferro e $2^{\circ}$ Simpósio Brasileiro de Aglomeração de Minério de Ferro, 15 a 18 de setembro de 2014, Belo Horizonte, MG, Brasil.
} 


\section{INTRODUÇÃO}

O cenário mundial de carvões sofreu variações ao longo dos anos por falta de demanda por parte das siderúrgicas, o que impactou nos preços médios de alguns carvões, principalmente os carvões alto voláteis $(\mathrm{AV})$ e baixo voláteis (BV) americanos, que tiveram uma queda acentuada. Por outro lado, teve-se uma maior oferta de coque verde de petróleo (CVP) no mercado

A participação de AV e CVP no mix da Usiminas situava entre $20 \%$ a $25 \%$. No caso do CVP, o consumo era restringido em $12 \%$ devido baixa disponibilidade de material no mercado.

Em função do cenário, foi proposto alterar o mix de carvões para coquerias, aumentando a participação de carvões AV americanos para 35\% e de CVP para $25 \%$.

O carvão AV tem como característica alta fluidez, granulometria grosseira $(45 \%<2,83 \mathrm{~mm})$ e índice de britabilidade hardgrove (HGI) baixo, com valores próximos de 50. Ele é classificado como um material duro, portanto, necessita de uma britagem eficiente a fim de adequar sua granulometria.

O CVP tem alto teor de inertes (considera-se em torno de $80 \%$ ), que são nucleadores e propagadores de fissuras devido as diferenças de contração em relação à matriz reativa de coque, causando fissuração. Neste caso, utiliza-se esse material numa granulometria mais fina, visando elevar sua participação na mistura.

De acordo com Reis e Ulhôa [1], o coque metalúrgico tem um papel importante nos altos-fornos e um dos seus principais atributos é garantir uma permeabilidade adequada para a passagem dos gases ascendentes. Para isso, é importante que ele tenha uma resistência física adequada. Os principais parâmetros de qualidade do coque requeridos pelos altos-fornos na Usina de Ipatinga são a resistência mecânica (Drum Index DI15/150) e resistência estrutural (Coke reactivity index - CRI e Coke strenght after reaction - CSR), além da qualidade química.

A granulometria da mistura de carvões é um dos principais parâmetros de controle de qualidade com forte influência sobre a resistência do coque (DI15/150) e também na produtividade (densidade de carga). Na figura 1 é mostrada a influência da granulometria no DI15/150. Observa-se que de maneira geral, uma granulometria mais fina melhora o DI15/150.

* Contribuição técnica ao $44^{\circ}$ Seminário de Redução de Minério de Ferro e Matérias-primas, 15ํ Simpósio Brasileiro de Minério de Ferro e $2^{\circ}$ Simpósio Brasileiro de Aglomeração de Minério de Ferro, 15 a 18 de setembro de 2014, Belo Horizonte, MG, Brasil. 


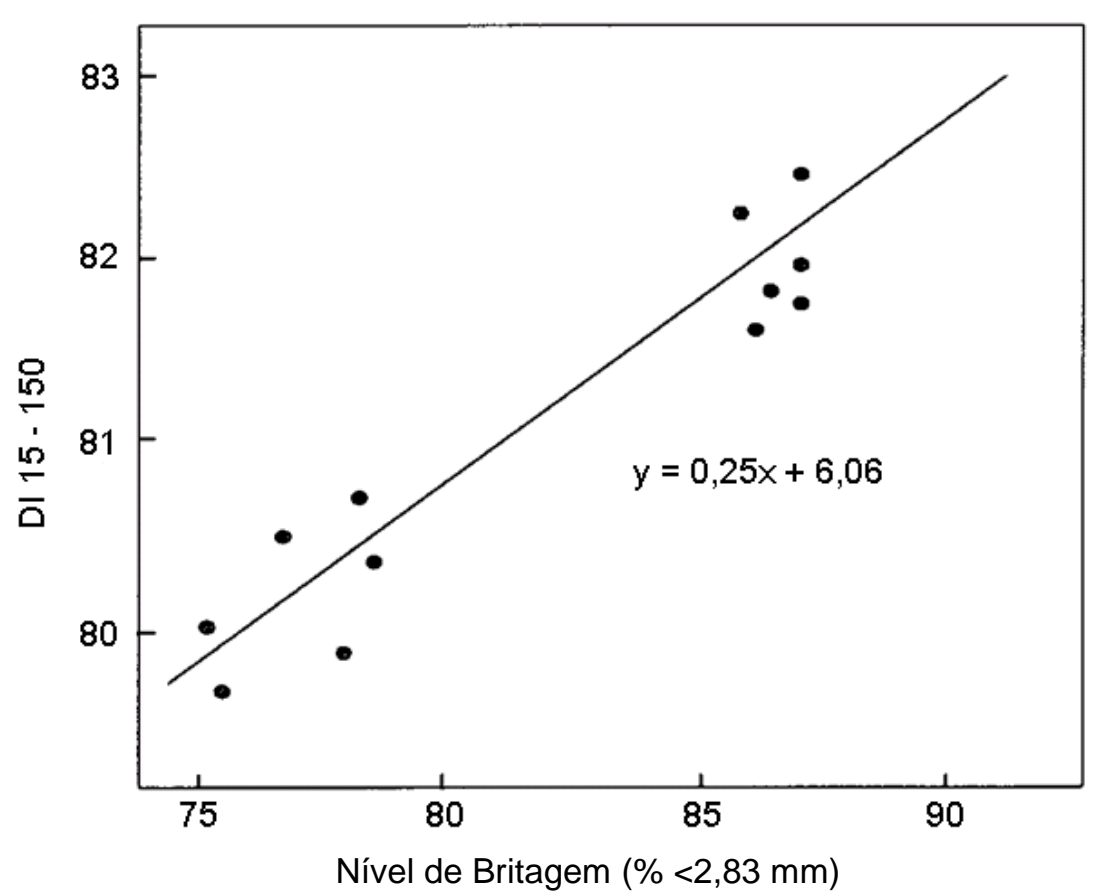

Figura 1. Relação entre DI15/150 e granulometria [2].

Segundo Ulhôa [2], a redução dos tamanhos proporciona uma mistura mais homogênea, possibilitando melhor aproveitamento das propriedades aglutinantes dos macerais reativos e melhor aglomeração dos macerais inertes pela matriz reativa, com formação de coque de melhor qualidade.

O teor de inertes na mistura também é um fator importante para qualidade do coque. Para Kojima e Sakurai apud Ulhôa [2], há uma proporção ideal de inertes para cada nível de rank, a fim de obter o máximo de DI15/150 e CSR do coque. Nas figuras 2 e 3 são mostradas as relações de DI15/150 e CSR em função da reflectância da vitrinita e o teor de inertes.

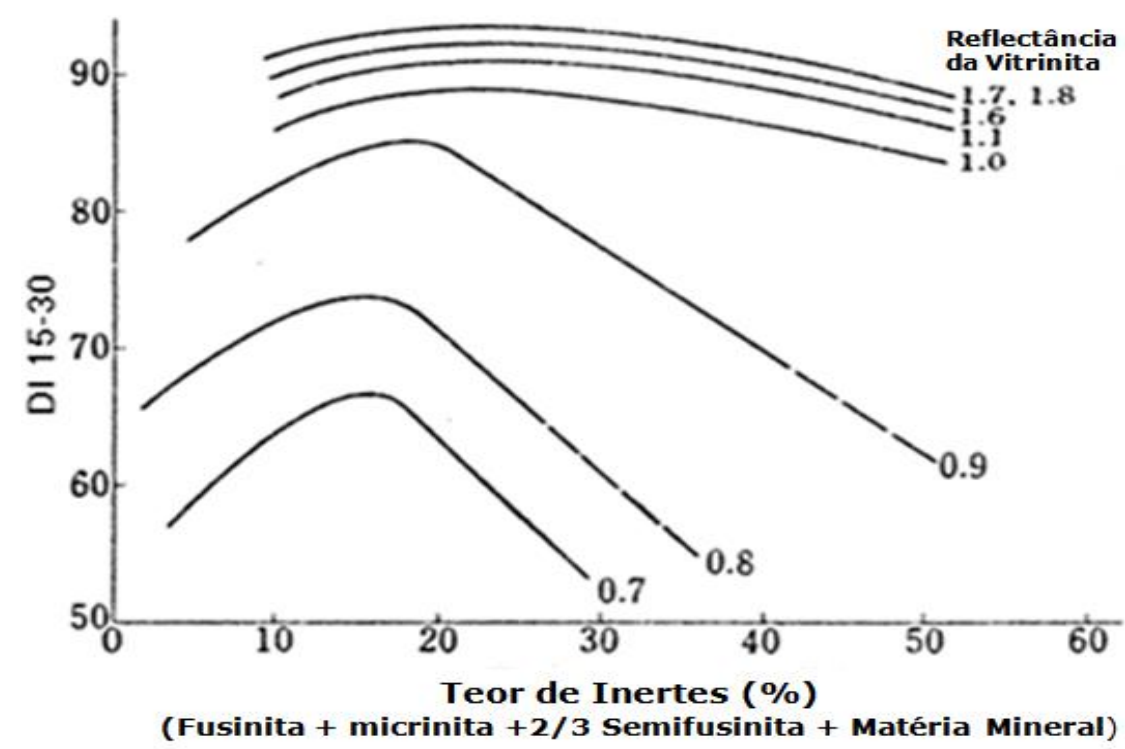

Figura 2. Relação entre DI15/150 e teor de inertes [2].

* Contribuição técnica ao $44^{\circ}$ Seminário de Redução de Minério de Ferro e Matérias-primas, $15^{\circ}$ Simpósio Brasileiro de Minério de Ferro e $2^{\circ}$ Simpósio Brasileiro de Aglomeração de Minério de Ferro, 15 a 18 de setembro de 2014, Belo Horizonte, MG, Brasil. 


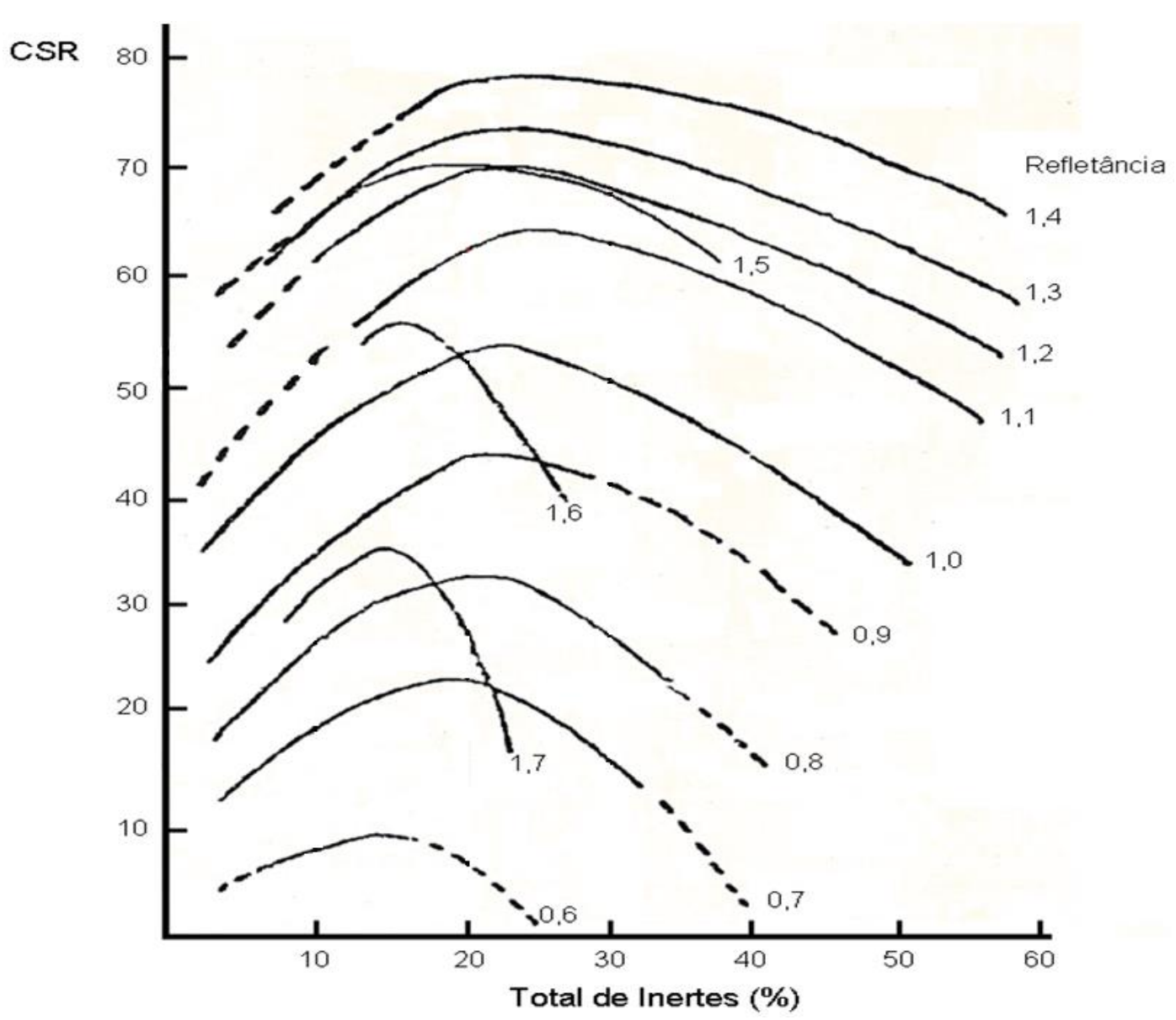

Figura 3. Relação entre CSR e total de inertes [2].

Caso não se tenha uma adequada proporção entre reativos/inertes pode ocorrer as seguintes situações:

$>$ excesso de inertes, quando a quantidade de macerais reativos é insuficiente para aglomerar os macerais inertes e um coque friável é produzido e

$>$ deficiência de inertes, a quantidade de macerais reativos é excessiva e a massa de coque torna-se muito porosa e um coque fragil é produzido.

O controle da granulometria é importante, pois melhora a resistência do coque e possibilita a utilização em maior proporção de carvão de baixa habilidade aglutinante.

$\mathrm{Na}$ Usiminas a britagem é realizada para cada carvão individualmente em britadores de impacto (figura 4). O controle de britagem é feito através de regulagem das aberturas das lâminas e da taxa de alimentação, permitindo assim maior controle na granulometria dos carvões e, consequentemente da mistura.

* Contribuição técnica ao $44^{\circ}$ Seminário de Redução de Minério de Ferro e Matérias-primas, $15^{\circ}$ Simpósio Brasileiro de Minério de Ferro e $2^{\circ}$ Simpósio Brasileiro de Aglomeração de Minério de Ferro, 15 a 18 de setembro de 2014, Belo Horizonte, MG, Brasil. 


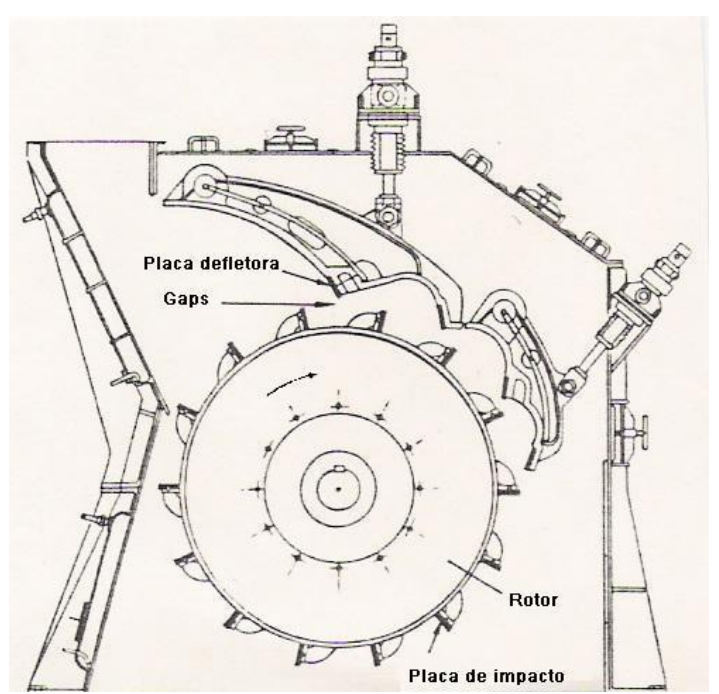

Figura 4. Desenho esquemático do britador de impacto

O nível de referência de britagem para cada carvão é em função da habilidade aglutinante e total de inertes, conforme mostrado na figura 5.

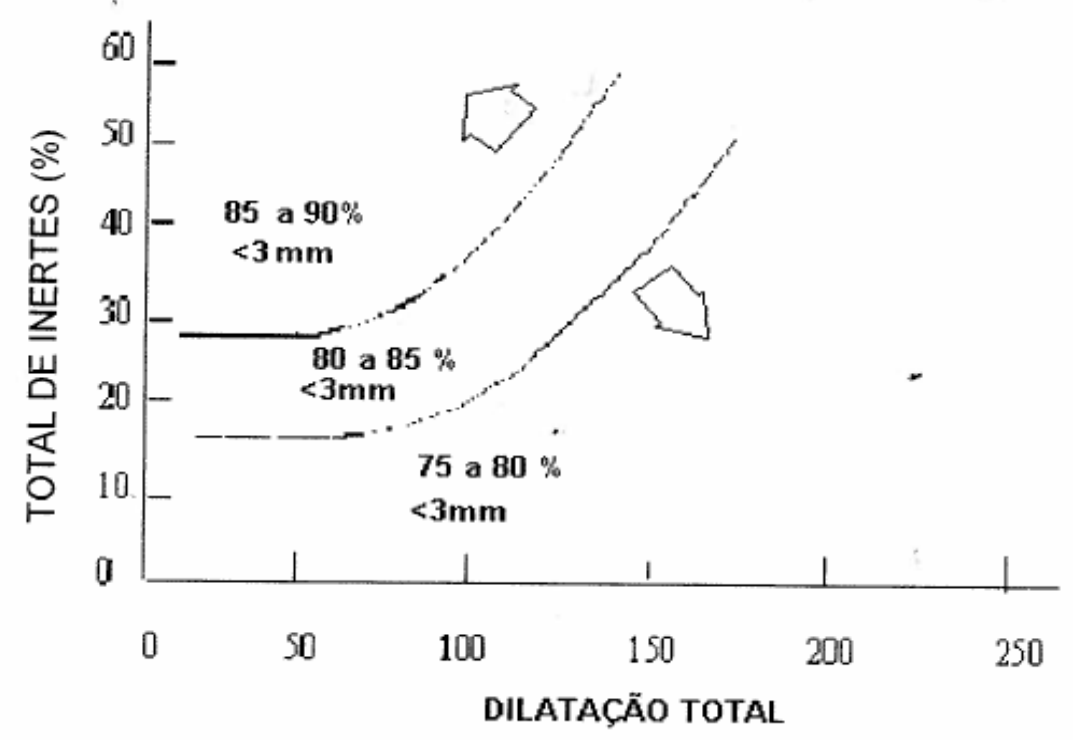

Figura 5. Nível de Britagem para carvão individual em função da dilatação total e teor de inertes [2]

\section{MATERIAIS E MÉTODOS}

Foi realizado um levantamento no banco de dados industrial das coquerias de Ipatinga no período de 20 meses, visando mostrar o comportamento da qualidade do coque no período anterior e posterior a elevação da participação do carvão AV e do CVP na mistura.

* Contribuição técnica ao 44ํㅗㄴ Seminário de Redução de Minério de Ferro e Matérias-primas, $15^{\circ}$ Simpósio Brasileiro de Minério de Ferro e $2^{\circ}$ Simpósio Brasileiro de Aglomeração de Minério de Ferro, 15 a 18 de setembro de 2014, Belo Horizonte, MG, Brasil. 


\section{RESULTADOS E DISCUSSÃO}

A Usiminas, Usina Ipatinga, possui duas coquerias, sendo que a Coqueria 2 é composta pelas Baterias 3 e 4, com 55 fornos de 6 metros cada e a Coqueria 3 , composta pelas Baterias 5 e 6 , com 40 fornos de 6 metros cada.

A seguir são apresentados os resultados num período de 20 meses, destacando a elevação da participação de AV e CVP (área hachuriada).

Nas figuras 6 e 7, são mostrados os resultados de granulometria $(<2,83 \mathrm{~mm}$ e $<0,105 \mathrm{~mm})$.

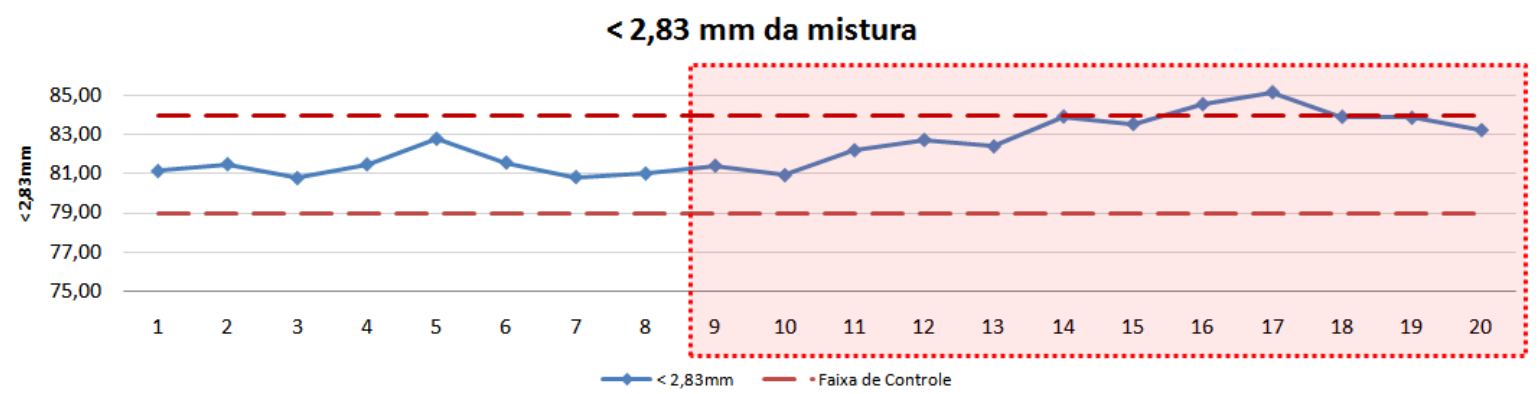

Figura 6. Granulometria $<2,83 \mathrm{~mm}$

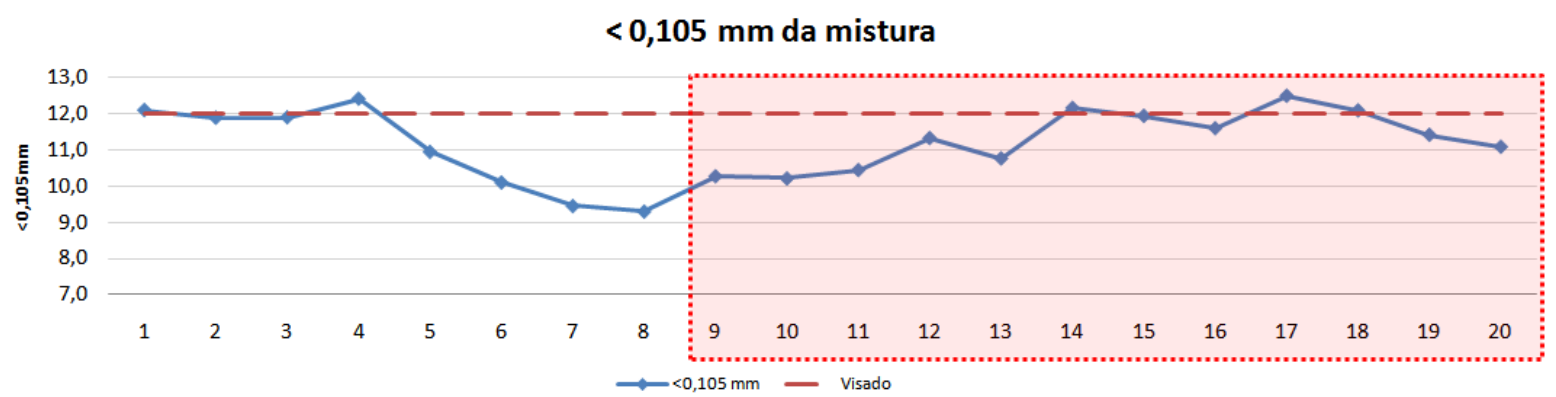

Figura 7. Granulometria $<0,105 \mathrm{~mm}$

Em função da maior participação de AV e CVP na mistura foi visado um controle da granulometria próximo da faixa superior, garantindo a britagem mais fina desses materiais. Foi definida uma rota preferencial para os carvões AV e CVP, com os britadores mais fechados. Também foi implementada uma periodicidade para troca de lâminas dos britadores em função do seu desgaste.

Os resultados obtidos de qualidade do coque são mostrados nas figuras 8 (DI15/150), 9 (CSR) e 10 (CRI) para as duas coquerias da Usiminas, em Ipatinga.

\footnotetext{
* Contribuição técnica ao 44 Seminário de Redução de Minério de Ferro e Matérias-primas, 15ํ Simpósio Brasileiro de Minério de Ferro e $2^{\circ}$ Simpósio Brasileiro de Aglomeração de Minério de Ferro, 15 a 18 de setembro de 2014, Belo Horizonte, MG, Brasil.
} 
Coqueria no 2 - DI 15/150 (\%)

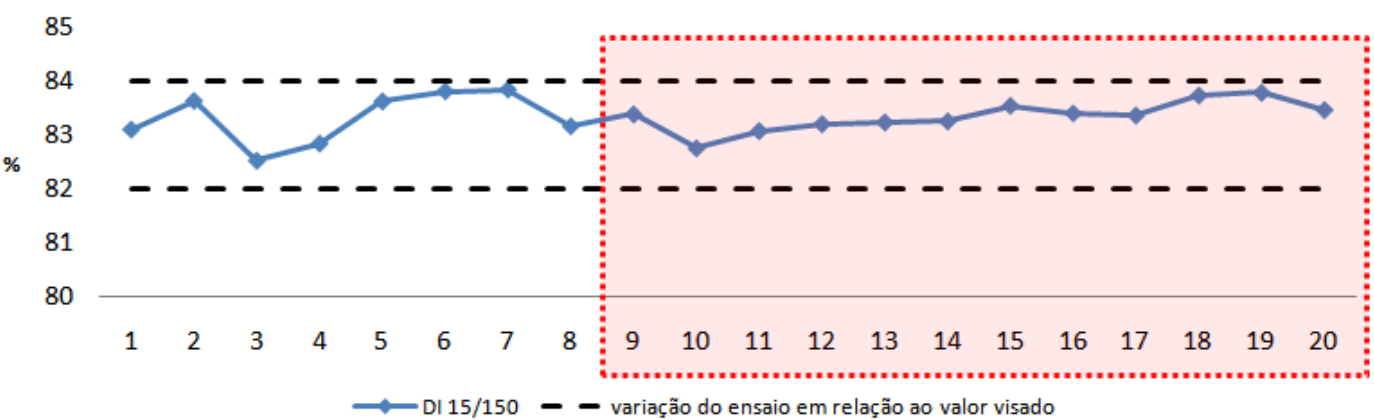

\section{Coqueria no 3 - DI 15/150 (\%)}

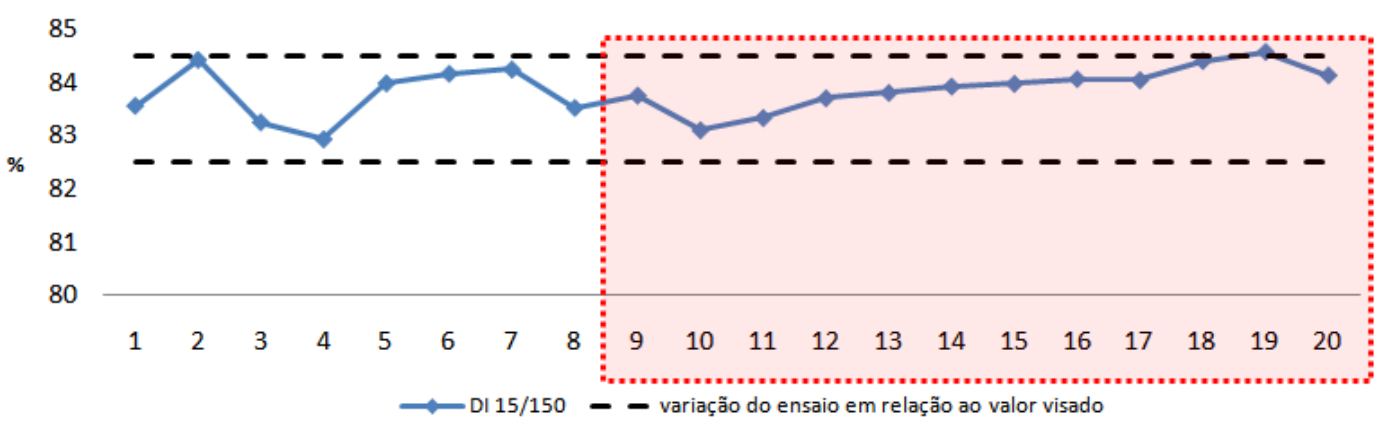

Figura 8. DI15/150 das coquerias no 2 e 3.

\section{Coqueria no 2 - CSR (\%)}

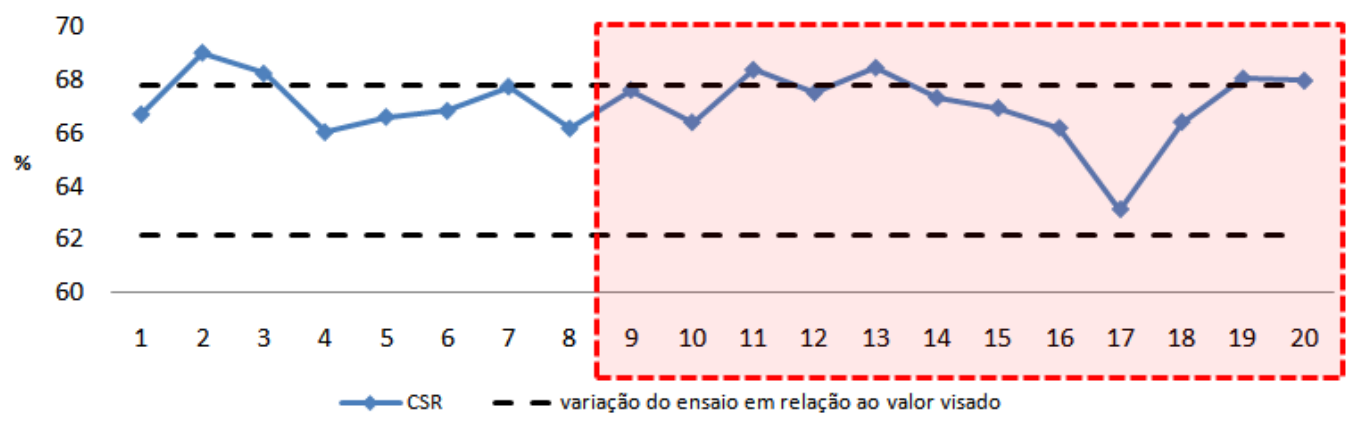

\section{Coqueria no 3- CSR (\%)}

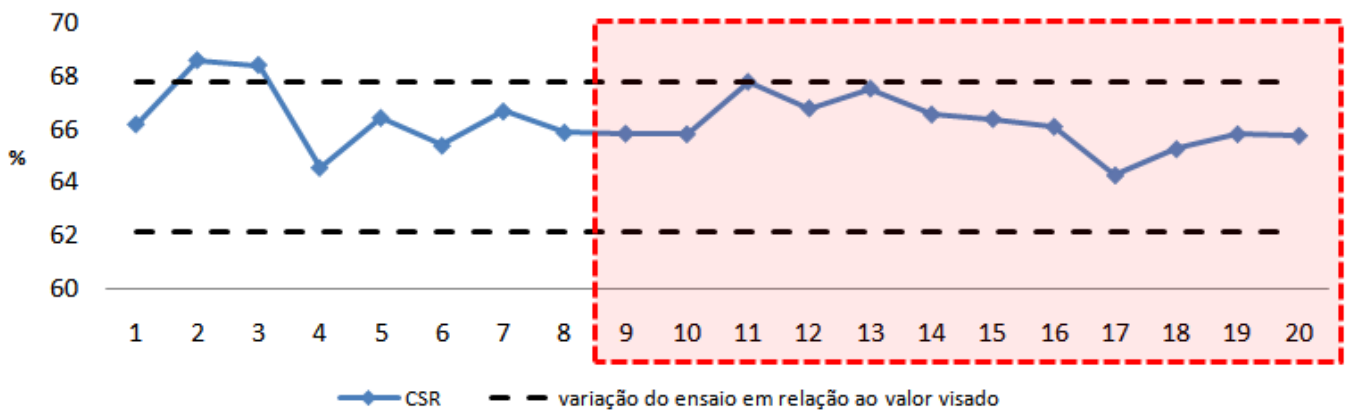

Figura 9. CSR das Coquerias № 2 e 3.

* Contribuição técnica ao $44^{\circ}$ Seminário de Redução de Minério de Ferro e Matérias-primas, 15은 Simpósio Brasileiro de Minério de Ferro e 20 Simpósio Brasileiro de Aglomeração de Minério de Ferro, 15 a 18 de setembro de 2014, Belo Horizonte, MG, Brasil. 


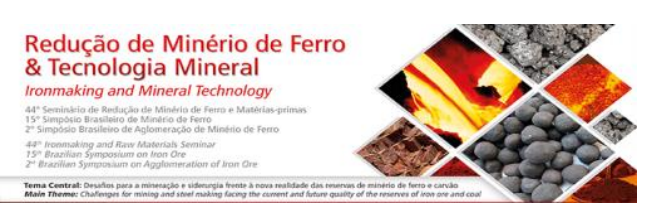

Coqueria no 2 - CRI (\%)

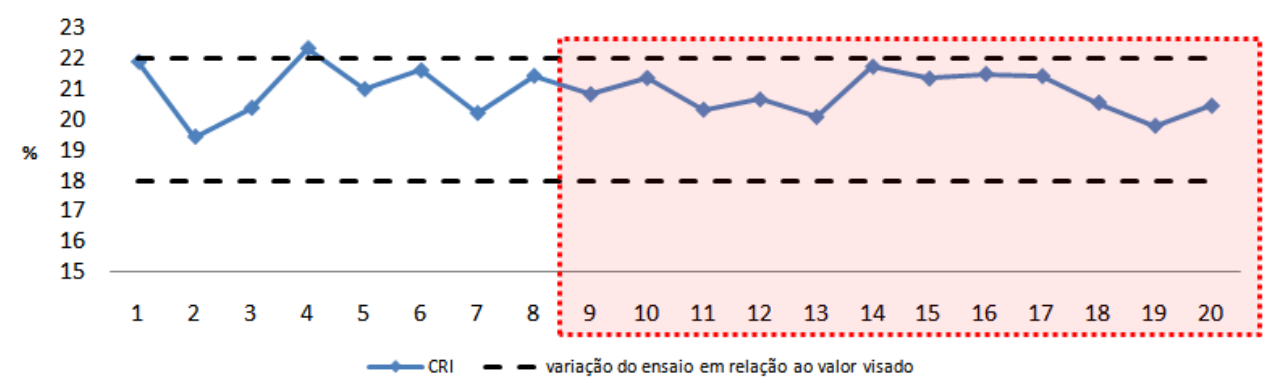

Coqueria no 3 - CRI (\%)

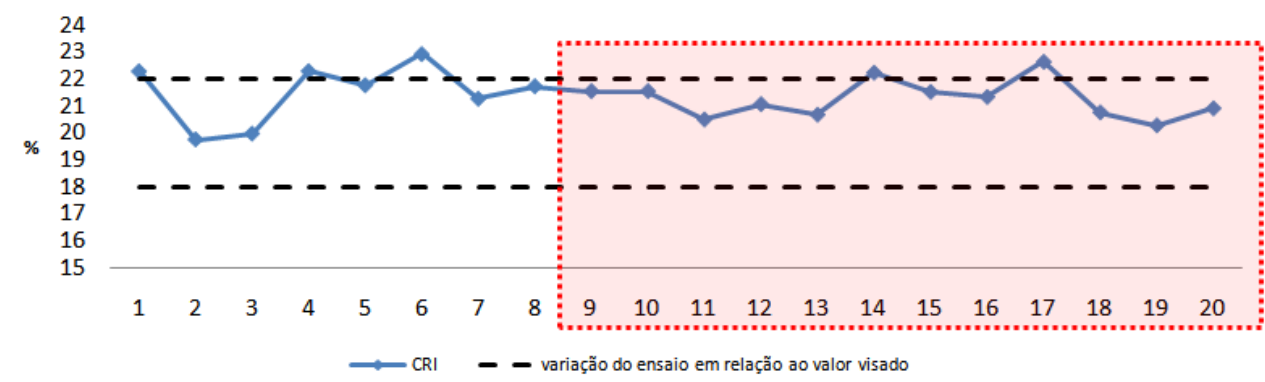

Figura 10. CRI das coquerias № 2 e 3 .

Os resultados mostraram que os resultados de DI15/150 e CRI não sofreram variações significativas com a elevação da participação do carvão AV e CVP, permanecendo dentro da faixa de variação do ensaio. No 17ำ mês teve uma queda do resultado de CSR em função da utilização de um carvão na mistura que estava contaminado, ou seja, qualidade inferior à desejada (CSR).

Ressalta-se que, a partir do $18^{\circ}$ mês foi iniciado a utilização de óleo diesel na mistura da Coqueria no 3 . O óleo diesel proporcionou aumento da densidade de carga e também uma melhoria na qualidade do coque, principalmente no DI15/150.

\section{CONCLUSÃo}

A elevação da participação de carvões AV e CVP, aliada ao maior controle de britagem, proporcionou manter os índices de qualidade do coque dentro dos parâmetros desejados. Além disso, a utilização de óleo diesel contribuiu para o aumento da densidade de carga e, consequentemente melhoria da resistência mecânica (DI).

\section{Agradecimentos}

A Usiminas pela oportunidade, a Gerência Geral de Redução pelo apoio ao desenvolvimento desse trabalho.

\section{REFERÊNCIAS}

1 Reis HB, Ulhoa MB. Qualidade de Coque de Alto-Forno, Contribuição Ténica ao XXX Seminário de Redução de Minério de Ferro da ABM, 1999.

2 Ulhoa MB. Curso de Carvão Aplicado a Fabricação de Coque de Alto-Forno.

* Contribuição técnica ao 44 Seminário de Redução de Minério de Ferro e Matérias-primas, 15ㅇ Simpósio Brasileiro de Minério de Ferro e 2o Simpósio Brasileiro de Aglomeração de Minério de Ferro, 15 a 18 de setembro de 2014, Belo Horizonte, MG, Brasil. 